\title{
Fictionalising Jurisprudence: An Introduction to Strong Legal Fictionalism*
}

\author{
David Gawthorne $^{\dagger}$
}

\section{Introduction}

Fictionalism can be taken as the view that the characteristic propositions expressed in a given discourse may turn out to be false and, yet, reasons might remain to continue engaging in the discourse without radical revision. The approach of fictionalism is increasingly being put forward as a rival to realism in areas of discourse that are difficult to reconcile with a naturalistic metaphysics and epistemology. Moral fictionalism has received significant attention and the characteristics that make putative moral facts difficult to square with naturalism are common to all normative discourse. For this reason, legal fictionalism, ie, fictionalism about the truth claims of legal discourse, is not novel. For example, Spector suggests a form of legal fictionalism characterised by the dual claims that legal statements represent normative propositions and that competent users of legal language should not believe those propositions. ${ }^{1}$ Spector then resorts to sceptical arguments that challenge the grounds of all normative truths, to theoretically motivate his legal fictionalism.

Yet, legal discourse is not purely normative. I prefer to motivate legal fictionalism by focusing on fictionalism in ontology. Field advanced fictionalism as a rival to realism in Anglophone ontology with his argument against Quine's view that, because ontological commitment to numbers is indispensable to our best scientific theories, numbers effectively exist as abstract entities. ${ }^{2}$ Field counters that numbers are dispensable, but acknowledges that talk of numbers is a useful fiction for making predictions about the concrete, physical world. Albeit for different reasons, the things to which legal discourse expresses ontological commitment should be regarded in the same way. This has significant consequences for the way that we may conceive of legal practices, generally, and judicial decision-making, in particular. As the resulting

\footnotetext{
* Part of this article was presented as a paper at the Annual National Conference of the Australian Society of Legal Philosophy, Sydney Law School, 17 August 2013. I thank various conference attendees, as well as anonymous referees, for their constructive comments.

$\dagger \quad \mathrm{BA} / \mathrm{LLB}$ (UWS) Ph D (UNE), currently studying education at UNE.

1 Horatio Spector, 'Legal Fictionalism and the Economics of Normativity' in Mark D White (ed) Theoretical Foundations of Law and Economics (Cambridge University Press, 2009) 57. Hartry H Field, Science without Numbers (Princeton University Press, 1980) 1-7.
} 
view of adjudication affirms much in our existing adjudicative practices, including the ideal of objectively correct legal decisions made by means of independent legal reasoning, the claims of legal fictionalism are of more than mere theoretical interest.

At section II of this article, I set out a theoretical motivation for legal fictionalism by first proposing a departure from Hart's legal positivism. Essentially, I note that Hart's focus on legal rules, and norms generally, was at the expense of attention to a broader legal ontology. Closer attention to legal things can lead to a further departure, from legal positivism to legal fictionalism. In particular, attention is given to the seemingly supernatural powers of creation and control that mere mortals exercise over legal things, as a subclass of socially constructed things. This alternative focus brings to the fore a dilemma of uncharitableness concerning the ontological commitments expressed in the discourse of whole societies about such things. Either, there is widespread equivocation as to the fundamental concept expressed by terms such as 'existence' or our claims about legal and other institutional things are never really true. When stated as a dilemma, rather than assuming either horn from the outset, our broader social practice of fiction-telling yields a reason to prefer the fictionalist horn.

At section III, I differentiate three grades of legal fictionalism and contrast strong legal fictionalism with Spector's weak form. Only the stronger form has it that engagement in a fictional discourse of law can provide reasons for legal decisionmaking independent of moral opinions or policy considerations. This stance relies on the claim that maintaining a fictional discourse with respect for its integrity justifies inferences to conclusions about a fictional domain beyond what is described in existing expressions of the discourse. Focusing on ontology allows an analogy between a fictional discourse of law and literary or popular fiction, in which context such inferences are more obviously persuasive. At section IV, I argue that this notion of respect for the integrity of such a discourse saves legal formalist jurisprudence from the indeterminacy objections of legal realists.

Section V concerns a way of analysing the concept of law in order to demarcate law as against other aspects of social life, and, at section VI, I suggest that the intuitive demarcation between moral and legal norms is explained by the distinction between fictional and realistic discourses. The latter kind of discourse is characterised by the truth of its characteristic propositions. Section VI closes with a first pass at the best reason to continue engaging in a discourse of law, without radical revision, after recognising it as fiction.

\section{Fictionalism over positivism}

One seeking to advance a theory in legal philosophy does well to begin with points of departure from H L A Hart's, The Concept of Law. Most notably, Dworkin criticised 
Hart's neglect of principles in favour of a focus on rules. ${ }^{3}$ The departure, here, highlights a further deficiency of that focus. The discourse of law not only concerns principles and rules, but also things. Legal things are entities, events and states of affairs that characteristically feature in legal discourse, such as states, courts, bodies corporate, trusts, offences, convictions, powers, capacities, instruments etc. Refocusing attention upon such legal things can lead to a new understanding of the nature of legal discourse. Consider the claim often found in legislation that, by means of its proclamation, an entity is created. The following legislative provision is an example:

\section{Creation of Court}

(1) A Court, to be known as the Family Court of Australia, is created by this Act.

(2) The Court is a superior court of record.

(3) The Court consists of:

(a) a Chief Judge, who shall be called the Chief Justice of the Court;

(b) a Deputy Chief Judge, who shall be called the Deputy Chief Justice of the Court; and

(c) Judge Administrators, Senior Judges and other Judges, not exceeding, in total, such number as is prescribed. ${ }^{4}$

The Court is created upon the commencement of the constituting legislation. Though the Australian Government may have delayed commencement until building space was assigned to the Court and a minimum number of judicial appointments were made, this would not have been deemed necessary for the creation of the Court to be effective. The Court is a distinct entity. Whilst this is but a lone example, it is by no means peculiar.

Though such a claim of creation is casually made and accepted in legal discourse, it is not usually taken at face value when it comes to theorising about legal things. The ontological commitment expressed by it - that is, the commitment it expresses or presupposes to the existence of things of certain kinds - is rendered equivocal, so that the purported act of creation means something different to the creation of physical objects, such as pottery, office buildings and ocean liners. More generally, this approach features in social ontology with a broad commitment to realism, as it analyses social discourse concerning money, games, and institutions including non-individual bodies and languages. ${ }^{5}$ It prompts the question as to what the principled basis could be for suspecting equivocation in our expression of ontological

Ronald Dworkin, Taking Rights Seriously (Harvard University Press, 1978) 22-31.

Family Law Act 1975 (Cth) s 21.

John R Searle, The Construction of Social Reality (Free Press, 1995) 190; John R Searle, Making the Social World: The Structure of Human Civilization (Oxford University Press, 2010) 18. 
commitment as it relates to legal and other institutional things, on the one hand, and less controversially physical things, on the other.

The answer lies with the dependence of socially constructed things on our representation of them: it is in virtue of our attitudes towards legal and other institutional things that they have their being. They are created, modified, destroyed and otherwise dealt with in accordance with the consensus of a community or by the declaration of those authorised by consensus. Hart's social rules are things such as these. They exist in virtue of a sufficient mass of community members accepting them, where such acceptance manifests as a critically reflective attitude towards certain behaviour, displayed in criticism, demands for conformity and the justification of those demands using normative language. ${ }^{6}$ Yet, if everyone in a community believes in ghosts, and exhibits a comparable attitude of acceptance as to the intentional states of ghosts, ghosts do not thereby exist for that community. The normative quality of rules is not the distinguishing aspect, here, as all institutional things are similarly dependent on the mental states or linguistic practices of a community. ${ }^{7}$

More acutely, there can be $n$ entities of a kind in the world at one moment and $n+1$ at the next, in virtue of an authority representing the world as being that way, but only if it is a kind more like that of corporations than that of angelic hosts. In short, the perfectly reliable and causally unmediated influence of minds over a domain of institutional things is so far beyond the natural powers manifested by human individuals and groups when otherwise interacting with the world as to make it implausible to keep such events of creation, and states of affairs of maintenance, on par with the creation and maintenance of things of other kinds. Declaring our ontological commitment to institutional things to be sui generis, and thus differentiating the way in which institutional and other things are said to exist, is one way to alleviate this implausibility, as the creation of institutional things and the creation of all other things then cease to be on par.

Yet, there is a way to achieve the same end without denying that expressions of ontological commitment are univocal, including as expressed in relation to legal and institutional things. The supernatural act of creation apparently entailed by a declaration of existence in virtue of the declaration is rendered mundane once we recognise its context in fiction. For example, we readily accept that the birth of a person is grounded in nothing more than a description of her birth, without equivocation as to the meaning of terms such as 'birth', 'person' and 'exist', if the attitudes constituting our acceptance are pretended. ${ }^{8}$ So, it is arguably the mark of a

$6 \quad$ H L A Hart, The Concept of Law (Oxford University Press, $2^{\text {nd }}$ ed, 1994) 57.

7 Searle, above n 5, The Construction of Social Reality, 32.

8 John R Searle, 'The Logical Status of Fictional Discourse' (1975) 6(2) New Literary History 319, 325-6. In his analysis of fiction, Searle employs genuine speech acts disengaged from their world orientation by additional conventions. Pretence may be explained better as genuine attitudes disengaged by some further mental state, given phenomena such as desires directed to fictional outcomes; cf Amy Kind, 'The Puzzle of Imaginative Desire' (2011) 89(3) Australasian Journal of Philosophy 421. 
fictional thing that it has its being in virtue of nothing more than representations of it. This mark may be discerned on legal things, which leads us towards fictionalism about legal things and, indeed, fictionalism about all institutional things.

Admittedly, such an explanation requires that the meta-attitudes, or other means by which attitudes are pretended as regards fiction, have commonly been epistemically opaque to the individuals who harbour them. However, there is a likely precedent for this in the personae that individuals present to others, especially in formal social settings. These personae may be regarded as fictions, in that they diverge from a genuine character expressed in other contexts. Further, we often fail to reflect on these personae as pretences. Notably, Sartre dubbed this common circumstance 'bad faith', though he goes to the extreme of denying that we possess a genuine character. ${ }^{9}$

Of greater concern are the formidable intuitions that this fictionalist approach runs up against. Many will see it as excessively uncharitable to attribute so many false beliefs to most in a society, concerning social ontology. However, a non-disruptive fictionalism is being proposed. It is not suggested that anything should change in the discourse that expresses our folk social ontology, solely on the basis that it is false, strictly speaking. This conservative stance should diminish the force of the opposing intuitions. Further, though there is a distinct lack of charity inherent to fictionalism about institutional things, the scene is more complex than that.

In fact, we are faced with the dilemma of having to forgo one of two kinds of charity. Either we can be uncharitable with respect to the broad range of false statements attributed to society about institutional things, or we can be uncharitable with respect to the discontinuity of concept expression that we attribute to everyone and in relation to such a fundamental concept as existence. Indeed, the apparent audacity of the claim that money, games, non-individual bodies, legal instruments and languages do not really exist must be balanced by an appreciation of the viable alternative: that they only exist in an alien sense. Due to the dependence of institutional things upon our attitudes towards them, which either approach must accommodate, it will make no practical difference as to whether they turn out to be fictions or quasiexistents. The determination comes down to the weighting of competing intuitions of charity.

When forced to choose between two such uncharitable options in conversation, we generally look to the broader context in order to break the tie. If someone claims to have been drinking orang-utan with breakfast for the past few weeks, one might infer that they were using an idiosyncratic term to express the concept of a fruit drink or one might infer that they were, indeed, claiming to have imbibed orang-utan for breakfast and that they probably do not speak the truth. ${ }^{10}$ The broader conversational context will

9 John-Paul Sartre, Being and Nothingness: An Essay in Phenomenological Ontology (Hazel E Barnes trans, Methuen, 1956) 87, 101-2.

10 Tyler Burge, 'Individualism and Mental Content' (1979) 4(1) Midwest Studies in Philosophy 73, 90-2. 
explain the nature of the deviance if it includes either a poor grasp of English or a jocular spirit, for example, and that context will be used to break the tie in the appropriate direction. As fictionalist uncharitableness is directed at the discourse of whole societies, the entire societal context must be looked to in order to break the tie, ie, in deciding whether everyone is continually telling untruths or performing a fallacy of equivocation. This societal context includes the practice of fiction-telling. Further, as was established above, analogising to the existing social practice of fiction-telling explains the acceptance of claims of creation in virtue of representation that are regularly made in the context of doing things with institutional and legal entities. So, this potential explanation is an appropriate tiebreaker between the two options of massive social uncharitableness presented by the case of institutional things.

Given the tiebreaker of the fiction-telling practice, fictionalism about institutional things should be preferred, unless theorists favouring equivocation can conceive of a better way to motivate their view, looking to the societal context. Searle attempts to provide such a reason. The starting point for Searle is an explanation of institutional facts. ${ }^{11}$ This is in contrast to brute facts, which are about things that exist independently of mental or linguistic representations, such as quarks, mountains and nebulae. Searle suggests that what is distinctive about references to institutional objects, is that they are merely placeholders for the linguistic articulation of human activities. ${ }^{12}$ For example, money is nothing beyond its function of providing a unit of value in all manner of transactions. ${ }^{13}$ Searle then infers that language or signs are partly constitutive of institutional facts. This partially linguistic constitution is what distinguishes institutional facts from brute facts and between ontological commitment as it may be expressed by the statement of each respective kind of fact.

Searle's argument for the linguistic constitution of institutional facts ultimately relies on his observation that, '[i]f you take away all the symbolic devices for representing [institutional objects], there is nothing else there. ${ }^{14}$ There are two senses in which Searle might be taken to be saying that there is nothing else there. First, he might be saying that there is nothing else there, really. There is only the representation of something, as with a fictional discourse. Second, he could mean that there is nothing represented, whether one is talking realistically or otherwise. It cannot be the first sense. That would be like saying that unicorns can only exist relative to a linguistic system for representing unicorns (eg, the noun 'unicorn'), because there are no unicorns, really. Clearly, there is something more to unicorns than 'unicorns', because unicorns are spoken of as having properties that 'unicorns' does not have. There is no need to reduce talk of unicorns to talk of 'unicorns' if we have an adequate theory of fictional semantics. Searle makes clear that this is not what he means. Rather, he claims that there is nothing with intrinsic properties to be represented and this is why

\footnotetext{
$11 \quad$ Searle, Making the Social World, above n 5, 33-5.

$12 \quad$ Ibid 52

13 Ibid 56-7, 60-1.

14 Ibid 66-7.
} 
linguistic expressions are essential to institutional facts. Olivecrona expressed a similar view. ${ }^{15}$

In response, we might well ask why we cannot represent purely institutional entities, which lack properties other than their social functional properties. They are strange when compared to real physical objects, but that only supports the claim that there are no such things, really. That there really are no such things as purely institutional entities is no more an objection to the representation of them than saying that there really are no unicorns is an objection to the representation of unicorns. So, apart from a lapse of the imagination, Searle has given us no reason to think that institutional entities having only social functional properties means that propositions about them do not represent the world as including institutional entities in the same way that propositions about insects represent the world as including insects. Accordingly, Searle's principled distinction between brute and institutional facts turns out not to be so principled. Along with that distinction goes the principled basis to distinguish between ontological commitment expressed in relation to physical things and that expressed in relation to institutional things. Fictionalising social ontology remains the only principled approach to explaining our fantastic powers over institutional things.

Once a fictionalist ontology of legal and institutional things is motivated, it can then be extended from legal ontology to all legal discourse, which could include primitively normative facts. This is warranted by the observation that the means employed in legal, legislative and judicial practice to create, modify and destroy legal things are the very same used to establish, develop and extinguish legal norms. For example, by means of the enactment and proclamation of the Family Law Act, not only was the Family Court of Australia created, but many legal rules and other legal norms were also established. The simpler hypothesis is that these common methods produce common fictional results.

It is not just legal things and norms established within a legal system that share a common means of establishment, development and extinguishment, but other institutional things and norms upon which legal systems depend according to prominent forms of legal positivism. As was raised above, Hart considered that rules, more generally, exist in virtue of community acceptance. Legal rules are but a certain kind, validated by a rule of recognition that is accepted by state officials as that from which all legal rules are ultimately derived. ${ }^{16}$ Shapiro points out that it is not circular to use the concept of an official to define law, because that concept has application in non-legal areas, such as with the dean of a university taken as a university official. ${ }^{17}$ As we conceive of the office independently of the person who assumes it, an office is an institutional entity, afforded its distinct character by a broader array of institutional

\footnotetext{
$15 \quad$ Karl Olivecrona, Law as Fact (Stevens, 2nd ed, 1971) 246-53.

16 Hart, above n 6, 116

$17 \quad$ Scott J Shapiro, Legality (Harvard University Press, 2011) 94.
} 
entities and relations. Such institutional entities are, as with social norms, created and maintained by a widely held belief in or acceptance of them.

The characterisation of legal discourse as fiction recasts Hart's distinction between external and internal points of view on the law, the former being the perspective of an anthropological or sociological study of behaviour and the latter, the perspective of one who has accepted certain practices as obligatory. ${ }^{18}$ With legal fictionalism, these points of view should be distinguished as external and internal to a fictional discourse. Just as an internal point of view on the Harry Potter stories concerns wizards and magic, and the external point of view concerns novels, authors and readers, the internal view on the law concerns legal things and the external view is the subject matter of sociology etc. This departure avoids the need for legal officials to be ideologically committed to the maintenance of the law.

Ehrenberg poses the problem of anarchist officials for legal positivists who ground the law in social facts such as the acceptance by legal officials of a rule of recognition from which other primary and secondary legal rules are validly derived. ${ }^{19}$ Given that the truth-makers of legal propositions are taken to be attitudes of officials, if the officials do not have the requisite attitude then there is no legal system. Ehrenberg then argues that it is conceivably possible for a legal system to remain operative though the key positions in the system are occupied by officials who do not accept, adopt or uphold the rule of recognition, but who instead fulfil the role of their station to avoid sanction or for other prudential reasons. As we clearly do have legal systems, and such legal systems would tolerate anarchist officials, Ehrenberg concludes that the brand of legal positivism that sees legal propositions as being made true by facts about the attitudes of officials cannot be right.

There are two reasons that defining the internal point of view as a fictional discourse avoids this problem. First, legal fictionalism avoids the problem of finding reliable truth-makers for legal facts, such as social facts. On one view, to ask what makes propositions expressed in a fictional discourse true is to misunderstand the nature of fiction. Truth in fiction is merely what is true according to a fictional discourse. Not only is a fictional discourse of law not true, except in the sense of what seems right to say is true when participating in legal discourse, but the sources of the discourse are themselves settled only according to the fiction. So, who is entitled to author the fiction of law (eg, officials) and what materials constitute the fiction (eg, legislation and case reports) form part of the subject matter of the fictional discourse. Apart from their designation as such within the relevant fictional discourse, officials have no real qualities that set them apart.

Second, our experience of fictional discourses with which we engage for the purpose of entertainment informs us that we can so participate without any

18 Ibid 89-91.

19 Kenneth M Ehrenberg, 'The Anarchist Official: a Problem for Legal Positivism' (2011) 36 Australian Journal of Legal Philosophy 89, 98-104. 
commitment to the reality of what is claimed within the discourse. We can reason about the worlds of Sherlock Holmes and Bilbo Baggins - even have desires directed to the aspirations of such characters - and yet remain able to distance ourselves from these discourses by means of our sense of reality. So, given that the law is another fictional discourse, an anarchist official could denounce the moral authority of the law and fail to believe in the things that feature in the legal discourse, according to their sense of reality. Yet, they could still reason and understand their role within the fictional discourse of law, in the same way that we can reason about what belongs in fictional worlds. Importantly, they could still recognise normative requirements according to the fictional discourse of the law, ie, the legal obligations being imposed upon themselves and other subjects of the law, just as well as one who really affirms and endorses the authority of the prevailing regime.

\section{Grades of legal fictionalism}

Once legal fictionalism is theoretically motivated by analogy to narrative fiction, it is then possible to distinguish between its weak and strong forms. Spector's legal fictionalism is an example of the former. He regards the fictional ideology of law as mere window dressing that conceals the true rationale for public decisions. Rules of inference that allow the derivation of legal obligation judgements perform an ideological function of advertising the ways in which state apparatuses validate themselves, in order to reduce policing and enforcement costs. Thus, the function of law is to facilitate cost-effective social control. ${ }^{20}$

By contrast, strong legal fictionalism sees a commitment to the integrity of the legal fiction as providing independent reasons for reaching divergent conclusions in legal adjudication and legislation, as compared to making decisions on the basis of moral or policy considerations. Indeed, in the context of adjudication, a failure to respect the integrity of a legal fictional discourse is apparent as a post-hoc justification of decisions made according to such considerations. That is, the sense that judicial activism is taking place is the sense that the integrity of the discourse has been subordinated to moral or policy considerations, rather than the reverse. Weak legal fictionalism therefore differs in that it does not regard the fictional discourse as having integrity beyond its authorship at will. So, respect for such integrity cannot provide an independent basis for elaborating on the extant materials of a fictional discourse of law, apart from policy reasons or the personal morality of the adjudicator. Law is reduced to a veneer over a pragmatic process of non-legal reasoning that would proceed in much the same way without the ideological trappings of law.

There is a position between strong and weak legal fictionalism. At one point, Kelsen wrote of the basic norm as a fiction that validates a given legal order. ${ }^{21}$ The

20 Spector, above n 1, 73-6.

21 Hans Kelsen, 'The Function of a Constitution' in Richard Tur \& William Twining (eds), Essays on Kelsen (Clarendon Press, 1986) 115-19. 
basic norm is presupposed in order to terminate the regress of legal norms. Otherwise, each legal norm would require a higher order norm for its validation, ad infinitum. A legal order is a hierarchy of legal norms, the highest tier of which is a constitution made valid by the fictional basic norm. The lowest tiers are individual norms mandating concrete conduct. The intermediate tiers determine the procedure of state organs for generating and applying the lowest tiers. As the constitution is grounded as valid by the fictional basic norm, there is a chain of validation from this fictional norm down to the lowest tier of legal norms.

We might call Kelsen's grounding of a hierarchy of legal norms by a fictional basic norm 'moderate legal fictionalism'. It is moderate in that the resulting legal order does provide independent reasons for making legal decisions, but these independent reasons are limited to circumstances in which a legal outcome may be deduced from higher legal norms that identify the relevant legal sources and the manner of applying them to a given factual scenario. Of course, it is widely recognised that the outcome of adjudication by superior appellate courts is often not determined deductively, due to the open-textured nature of language, ${ }^{22}$ the circular nature of legal concepts, ${ }^{23}$ diverse conceptions of legal concepts, ${ }^{24}$ or the simple under-determination or overdetermination of the result by precedent. The independent reasons for legal decisionmaking suggested by the moderate approach are, therefore, constrained by legal indeterminacy.

On the view of strong legal fictionalism, it is not really deductive reasoning that founds the independence of most legal decision-making, but the maintenance of a fictional discourse of law with respect for its integrity. Such integrity is best understood by analogy to literary and popular fiction. It might be thought sufficient, when fleshing out details not explicitly stated in a work of fiction, to ask the author for the answer. Then again, what if Sir Arthur Conan Doyle had been overheard confiding to a friend that he always imagined that Sherlock Holmes had internal organs made of mashed potato? The Sherlock Holmes stories have an integrity that the author fails to respect if he speaks in that way. ${ }^{25}$ In the same way, the fictional discourse of law has an integrity that an adjudicator may violate, even where the extant legal materials do not really determine the result. The 'gravitational force' of this integrity becomes even more obvious with narratives bearing less resemblance to reality, as in the genres of science fiction, fantasy and magical realism. Indeed, Priest demonstrated, with his

\footnotetext{
22 Hart, above n 6, 127-30.

23 Felix Cohen, 'Transcendental Nonsense and the Functional Approach' (1935) 35(6) Columbia Law Review 811, 820-1.

24 Dworkin, above n 3, 134-6.

25 This phenomenon is referred to in the philosophical literature as truth in fiction, though examples usually rely on the absence of any known authorial intention. For an influential analysis, see David K Lewis, 'Truth in Fiction' in Philosophical Papers, (Oxford University Press, 1983) vol 1, 261-80.
} 
short story Sylvan's Box, that even explicit logical contradiction can accord with the integrity of a carefully constructed narrative. ${ }^{26}$

The idea of attending to the integrity of a fiction of law obviously evokes Dworkin's theory of law as integrity. ${ }^{27}$ Yet, there is a substantial difference between Dworkin's concept of integrity and that at work in a theory of strong legal fictionalism. To illustrate, it is helpful to consider two similar, but relevantly different, analogies. Dworkin depicts the integrity of the law by comparing the law to a chain novel written by many authors in the conviction that they are writing the same story, with each given the responsibility for authorship of a single chapter. ${ }^{28}$ There are two aspects to the integrity of the chain novel writing process, as Dworkin sees it. First, any new material must fit the extant material in the sense of respecting and deferring to what has come before. Second, because each author is making the novel the best it can be, they must have a theory of what makes the kind of story that it is better or worse, and adhere to the standards thereby afforded in best developing the story within the constraints of fit. So, to attend to the integrity of the chain novel is to attend both to what fits and to an evaluative theory of the best novel of its kind.

Strong legal fictionalism dispenses with attention to Dworkin's second aspect. There is a dilemma for the legal fictionalist who would adopt Dworkin's analysis: either, the evaluation of a proposed narrative development is grounded in true evaluative propositions, or the evaluation is itself based on fictional standards. If the former, then the theory of law has departed from fictionalism. If the latter, then such a fictional theory of the best development of the story is either subsumed in the process of writing the chain novel in such a way as to fit with the extant materials or it undermines that process by importing extraneous fictional content that any further stage of the story must fit. Thus, making the story the best it can be is, at best, irrelevant and, at worst, a distortion of the narrative by means of an arbitrary extension of the extant materials. The strong legal fictionalist sees the integrity of the law, taken as a fictional discourse, as being solely related to fit with the extant materials. ${ }^{29}$

A second analogy, to the fan discourse surrounding a completed novel, is apt to illustrate the expansive concept of extant materials being employed in that claim. Lawyers and jurists contemplating hard cases should be compared to fans of a popular work of fiction, perhaps explaining how a particularly implausible act of heroism in a fiction is consistent with the physical laws of its magical setting or giving their view as to how a central character would have behaved in a situation that is only hinted at in the text. The concern of the literary fan is not the ongoing production of literature,

26 Graham Priest, Towards Non-being: The Logic and Metaphysics of Intentionality (Oxford University Press, 2005) 125-33. I thank an anonymous referee for suggesting this reference. Ronald Dworkin, Law's Empire (Harvard University Press, 1986) 225. Ibid 228-32.

29 For a similar account of truth in fiction as best fit, see Peter Alward, 'That's the Fictional Truth, Ruth' (2010) 25(3) Acta Analytica 347. 
importing normative considerations that apply to the evaluation of art, but elaboration on a fictional world that is only partly described or implied by the text on the page.

The preferred notion of fit is one of deference to the extant materials, as Dworkin would have it, but it is essentially non-normative and elaborations on the content of the extant materials are not seen as additional content. They are taken as expounding content already implicit in those materials, as with fan discourse about a novel. Yet, as any implication might be out of place in a sufficiently imaginative fiction and, so, there is nothing to a fictional discourse but that which is stated explicitly, it is not really true that such elaborations add nothing to the content of the extant materials. Rather, to participate in a fictional discourse is to assume the pretence that the content of the discourse goes beyond that which is explicitly stated. This pretence of transcendent and unified content is the integrity of a fiction and, for the legal fictionalist, the integrity of law. Consequently, Dworkin got a relation of dependence the wrong way around: an elaboration does not respect integrity because it fits the extant materials; it fits the extant materials because it respects their fictional integrity.

\section{Three kinds of judge}

The distinctions between weak, moderate and strong legal fictionalism can be clarified further by considering Tamanaha's argument as to how the conscious orientation of judges can undermine or uphold the Rule of Law. ${ }^{30}$ The Rule of Law is taken to consist of government being bound by rules fixed and announced beforehand in the use of its coercive powers. Tamanaha grants that there are subconscious influences on legal decision-making, such as biases of culture and class, but he claims that a kind of legal objectivity in adherence to legal rules is still possible given that the conscious attitudes and motivations of judges still have a causal effect that is irreducible to the effects of subconscious causes.

To this end, Tamanaha asks us to conceive of two kinds of judges: consciously rule-bound judges (CBs) and consciously ends-orientated judges (CEOs). The former consciously strive to abide by the binding dictates of applicable legal rules and the latter strive to achieve ideologically preferred ends, interpreting and manipulating the legal rules as necessary to achieve those ends. Tamanaha considers that there tends to be an important difference in the judgments of CBs and CEOs in that, over time, the decisions of CEOs will diverge from those of CBs. Further, that the judgments of CBs of all stripes will tend to converge in their outcomes, while the decisions of CEOs will not. So, the Rule of Law is evident in the striving to decide cases according to legal rules, resulting in the effects of a decrease in the probability of a decision being subconsciously influenced by background personal views and an increase in 
convergence between decisions founded on independent legal reasons within the same legal system.

An obvious limitation to this striving of $\mathrm{CBs}$ is that it falters when the $\mathrm{CB}$ encounters one of the subset of cases in which the legal rules are found to either underdetermine or over-determine the outcome. At this point, even the most faithful CB will have to yield to their view of the best ends in order to make sense of an incomplete or over-complete system. Tamanaha decries a return to the formalist view of the law as a unified and inherently coherent system, handed down from times immemorial or derived from the dictates of pure reason. ${ }^{31} \mathrm{He}$ accepts that there will be times when the law runs out and fails the adjudicator. He argues that this is not enough to warrant a global scepticism about legal objectivity.

Against Tamanaha's view, all of the law may be subsumed in a fictional discourse: both the uncontroversially complete parts and the controversial parts; both the claim as to what presently constitutes our legal system and claims as to its past descent or a priori derivation. The formalist fiction need not be regarded as an unfortunate myth of a bygone era, but merely another aspect of the way lawyers and judges talk when participating in the fictional discourse of law. This includes maintaining an attitude to under- and over-determining legal rule gaps and gluts to the effect that there is a pre-existing, transcendent law to be discerned and applied to plug the gaps and flatten out the gluts. It is an attitude of commitment to the fiction that there is a 'right answer' to be deduced by having regard to as much of the legal sources as is necessary to make sense of the legal discourse as it purports to describe an independent and characteristically legal domain.

The claim, here, is not that there really is a single right answer, but that the pretence privileges a single answer in reliance on reasons independent of moral and political predilections. Narrative fiction is generally indeterminate in that, though the transcendent content of a fiction goes beyond information explicitly stated in the authorised text, not every fact that must be either determinately true or determinately false, according to the integrity of the fiction, is thereby imagined to be epistemically determinate. For example, we cannot say how many hairs Sherlock Holmes had on his head at any given moment, though we may be committed to there being an unknown fact of the matter when reasoning about the story. Importantly, it is the integrity of the fiction that determines when information about a fictional world does or does not run out. Further, the indeterminacy of most narrative fiction need not be regarded as an essential feature of fictional integrity. Indeed, as Blackburn notes, it is a practical requirement of the genre of adjudicative law that a judge must find for one of at least two parties and this requirement regulates her attitude to the possibilities. ${ }^{32} \mathrm{He}$ also notes that, contrary to Dworkin's claims, the imperative to keep looking for independent reasons for deciding in the legal domain, and the ability to find them, does

$31 \quad$ Ibid 246.

32 Simon Blackburn, 'Truth, Realism and the Regulation of Theory' in Essays in QuasiRealism (Oxford University Press, 1993) 25-6. 
not commit the judge to the assumption that the right answer has any foundation in real facts.

We can call judges who strive to maintain a fictional discourse of law with respect for its integrity, and not just to conform to a body of legal rules that yield a simple consistency or completeness, consciously fiction-orientated judges (CFOs). CFOs are the exemplars of legal decision-making according to the strong form of legal fictionalism, CBs are according to the moderate form and CEOs are according to weak legal fictionalism. The judgments of CFOs are at least just as likely to exhibit convergence as those of their CB brethren. However, CFOs more effectively minimise the probability of their decisions being subconsciously influenced by background personal views, because the motive and ability to attend to independent reasons do not cease at the point of legal rule gaps and gluts.

Of course, it can be disputed that there is a significant distinction between the approach of the CFO and the post-hoc rationalisation of adjudication based on background personal views, but not by employing existing arguments for legal indeterminacy. Consider the argument offered by Leiter's rehabilitated American legal realism. Leiter attributes a method of naturalised jurisprudence to prominent historical figures of that movement. ${ }^{33}$ On this view, empirical inquiry into the causes of legal decisions tends to show that, primarily due to the multiple modes of interpretation of legal sources, legal decisions are not caused by legal reasons that are derived from the sources. ${ }^{34}$ At least in that important class of superior appellate cases, there are too many or too few legal reasons entailed by the legal sources to uniquely determine the outcome. In the absence of a rational procedure to derive uniquely privileged outcomes from legal sources, the vacuum is filled by a judge's political and moral predilections, or other, non-rational causes.

However, one's initial choice of concepts affects the conclusions to be drawn from the empirical data. Leiter's positioning of hard legal positivism as the conceptual presupposition of the legal realists sets up in advance the interpretation of judicial decisions as indeterminate with respect to legal reasons. ${ }^{35}$ In limiting the content of the law to that which is validly derived from a rule of recognition, Leiter only counts that which is explicit in the extant legal materials towards its content. Thus, the probable surplus or scarcity of legal reasons is due to the application of principles of interpretation and salience that are not entailed uniquely, in the real world, by the legal sources. Yet, fiction is precisely the way the world is not and law is fictional.

Just as decisions as to what documents and declarations count as legal sources are made from within a fictional discourse, the content of the extant legal materials is a fictional transcendent content. Thus, from an internal point of view, the legal reasons

\footnotetext{
33 Brian Leiter, Naturalizing Jurisprudence: Essays on American Legal Realism and Naturalism in Legal Philosophy (Oxford University Press, 2007) 40.

34 Ibid 74-5.

35 Ibid 65,72 .
} 
that may be validly derived from the extant legal materials are just the right number to uniquely determine the outcome of a legal controversy. Admittedly, the only constraint on this transcendent content is its fictional integrity. Yet, it is contended that this constraint plays a similar role to rule-following constraints in grounding the independence of reasons. It would beg the question against the constraint of integrity to argue that, it cannot be used to derive independent reasons, because it is not a rulefollowing constraint akin to deduction. Fictional integrity is suggested as a rational constraint that is different in kind from rule-following, which we utilise when reasoning about fictional situations.

It might still be thought that a rational constraint of integrity would typically be very weak, given the varied and sometimes outlandish character of narrative fictions that all exhibit their own integrity. The concern would be that such a weak constraint is susceptible to being overridden by moral and prudential reasons. This concern mistakes the diversity of the forms that the integrity of a narrative may take, as between narratives, for the weakness of its demands within what is taken as a single narrative. Instead, the strength of the constraint should be assessed by its manifestation in societies of fiction consumers, who discuss events lifted from cinematic and textual fiction with a casual ease of convergence, for the most part. Further, arguments about disputed aspects are had and won by invoking salient and cogent reasons. It is true that social facts about genre and intertextuality do some of the heavy lifting, but it should be remembered that such 'facts' turn out to be fictions on the view of fictionalism about social ontology. Thus, the impressive social phenomena of fictional content convergence and cogency are due to the constraint of integrity all the way down.

\section{A fictional concept of law}

The continuity between a fictional discourse of law and a broader fictional discourse of social norms and things was highlighted in section II, to motivate legal fictionalism. Therefore, the familiar problem of differentiating the subject matter of law from other aspects of social life becomes a particular concern for the proposed view. We might use an empirical method to discover the extension of our concepts, including that of law, which is to adopt Tamanaha's conventionalist way of identifying law. ${ }^{36}$ That is, law is whatever people identify and treat through their social practices as 'law'. The trouble with the conventionalist approach comes when we are first deciding which concept to employ in our theories before we go out to do the empirical research, in a way that does not either resort to mere stipulation or end up making an arbitrary catalogue of interconnected practices and linguistic terms.

In the search for a solution to this conceptual difficulty, one strong contender is Leiter's naturalistic approach of selecting concepts in the same way that scientists are thought to do, ie, on the pragmatic basis of whatever concepts are most fruitful to their

36

Brian Z Tamanaha, 'A Non-Essential Concept of Legal Pluralism' (2000) 27(2) Journal of Law \& Society 296, 313. 
empirical endeavour. ${ }^{37}$ Thus, the idea that we decide on our concepts before we do the empirical work is rejected. Rather, as we sail along in Neurath's boat, we revise both our empirical hypotheses and our concepts on a piecemeal basis, using criteria that work for us along the way. As Leiter would naturalise jurisprudence, he proposes to use the same method for selecting the relevant concepts in the study of law. He rejects as philosophically antiquated the view that conceptual analysis can be conducted from the armchair.

A second strong contender is Finnis' view that the only way to select concepts that relate to social institutions is by having regard to those concepts that are important or significant. ${ }^{38}$ Further, the only way to avoid the need to prioritise one subjective evaluation of importance and significance over others is to discern objectively normative principles that pick out the relevant concepts. More specifically, these are fundamental principles of human flourishing. A concept is selected based on the preponderance of central cases and cases are central if they are important for everyone to attend to in the promotion of human flourishing.

Against these promising approaches, if the legal discourse is fictional then looking for ways to identify salient concepts that are at home in a realistic discourse will have the effect of changing the subject. By adopting Finnis' approach, jurisprudence would import moral considerations that do not respect the integrity of the fictional discourse of law, in much the same way as was touched upon above in relation to Dworkin's theory of law as integrity. By adopting Leiter's approach, jurisprudence would be adapted to facilitate an empirical research program orientated towards the way the world really is, applying it to a fictional discourse that has no necessary relation to real states of affairs. The integrity of a fictional discourse of law is, once again, compromised by foreign conceptual criteria. Indeed, the only means of determining the concept of law that is likely to respect the integrity of the discourse is to locate the answer within the discourse. That is, there is no real difference between law and other aspects of social life. It is merely a claim of the fiction of law that there is. This makes more sense once we see the varieties of socially constructive discourse as distinct fictions. The identity of a fiction is, like the question of whether the characters of ostensibly distinct fictions could ever interact with each other, purely a matter of integrity.

An example of how selecting concepts by recourse to a realistic methodology changes the subject of the inquiry, so that they no longer fit with preceding conceptual analyses within the relevant fictional discourse of law, can be seen in the way realistic approaches do not accommodate the plasticity of legal concepts identified by Dworkin. ${ }^{39}$ According to his 'semantic sting' argument, either:

\footnotetext{
$37 \quad$ Leiter, above n 33, 134.

38 John Finnis, Natural Law and Natural Rights (Oxford University Press, $2^{\text {nd }}$ ed, 2011) 9-19.

39 Dworkin, above n 27, 37-45.
} 
(a) the disagreement in hard cases as to what falls under a legal concept is contrived by lawyers and judges to keep the truth from the public that the law does not always have an answer; or

(b) the use of competing criteria of application demonstrates that lawyers regularly talk past each other by failing to express the same concept with their use of the same types of terms.

We might agree with Dworkin that, given the way that controversy in hard cases actually plays out, both possibilities are equally implausible. It might then be thought reasonable to embrace a third option of rendering contingent the connection between concepts and their criteria of application (conceptions), so that people can share the same concept even though they apply distinct criteria of application. However, this approach has the drawback of making concepts mysterious entities, putting into doubt our epistemic access to them, ie, how we can ever know that we share the same concept with our peers apart from the brute insistence that we do.

A legal fictionalist can derive the same concept/conception distinction in a way that does not leave our epistemic access to the concept mysterious. The idea that different conceptions expressed by participants in a fictional discourse are genuinely conceptions of the same overarching concept is itself a fiction, propagated when the integrity of the discourse seems to require it. Our concept of law is such a fictional concept, so that the different criteria that get used to determine what the law is in a given case or series of cases evidences a merely fictional identity of concept between them. The lawyers and judges in these cases do really talk past each other, but the integrity of the discourse requires that they maintain the fiction that they are in conceptual agreement. Some might prefer to say that conceptual confusion just demonstrates that the lawyers arrived at the wrong answer. Yet, all fictions are almost entirely wrong from an external point of view, leaving only 'by its own lights' standards of correctness from an internal point of view.

It might be objected that fixed conceptual points are necessary for the coherence of a discourse and, therefore, for its integrity. On the contrary, equivocation can be conducive to the integrity of a fiction. Consider Lewis' discussion of the Sherlock Holmes story, The Adventure of the Speckled Band.$^{40}$ The murder in the story was achieved by means of a Russell's viper climbing a bell rope. The concepts exemplified by the viper apparently include both that of a kind of snake that can climb rope and that of a kind of snake that is categorised by the herpetological experts. Unfortunately, the experts will tell us that the Russell's viper is not a kind of snake that can climb ropes. We might explain this away by resorting to magic or concluding that Holmes actually

$40 \quad$ Lewis, above $\mathrm{n} 25,271$. 
got this one wrong, yet these options would not respect the integrity of the story. Integrity requires, therefore, that we allow the contradictory concepts to sit.

Even so, it should not be thought that the employment of equivocation to aid the integrity of a fictional discourse undermines the theoretical motivation for legal fictionalism, which eschewed equivocation as to our ontological commitments. The endorsed equivocation is local to certain arguments that may take place within the discourse and it is not really a necessary condition of it. Further, the context in which these arguments take place, such as the hard cases that lead Dworkin to propose his semantic sting, warrant an equivocal reading, whereas the eschewed equivocation was unwarranted.

The concept(s) of law approved of within a fictional discourse of law will, for historical reasons, be tied to a territory and its inhabitants. The consistent application of this concept of law to other territories and their inhabitants leads to a doctrine of mutual recognition of legality. Thus, while there really is no such thing as the French legal system, from within the French, US, UK and many other legal systems there is, because the concept of law employed in those fictional discourses of law also applies to fictional discourses participated in by the inhabitants of the other territories. This recognition of other legal systems need not be mutual. One fictional legal discourse may recognise another legal system that does not reciprocate. Further, such recognition is not limited to contemporary legal systems. The US fictional discourse of law may employ a concept of law that counts an Ancient Roman legal system as law and not merely as a system of orders backed by threats or some other non-legal form of social organisation.

Similarly, the question of whether or not international law is truly law is a question that can only be answered within a particular fictional discourse characterised by its participants as a legal discourse. Just as there can be mutual recognition of foreign legal systems according to concepts of law employed within each domestic fictional discourse of law, the same may be true as between domestic and international legal orders. So, international law may be counted as law both from the perspective of international law and from the perspective within a domestic legal system, though different concepts of law are employed in each fictional discourse. Further, international law may be seen as an atypical instance of law from within the domestic legal discourse, but as a typical instance of law from within the international legal discourse, and there is no right answer to the question of which concept is more correct standing outside the employment of concepts of law within each respective fictional discourse.

The same approach can also be applied to problems for theories of legal pluralism. Tamanaha summarises legal pluralism as the idea that there are all sorts of normative orders not attached to the state that, nevertheless, are law. ${ }^{41}$ These other normative orders include indigenous norms and institutions; the ruling-making power 
of social institutions such as religious hierarchies, corporations and universities; and possibly even community associations, sports competitions and family groups. The problem that Tamanaha then poses for legal pluralism is that such a generous view of what law is confuses the law with all normative orders. Other forms of normative order, including political norms, customs, habits, rules of etiquette and even table manners become law. The only apparent solution to the problem, says Tamanaha, is to isolate a concept of law that is independent of the state and, yet, capable of differentiating law from other forms of normative order. He goes on to argue that such a concept is untenable.

Yet, if the concept of law is defined within a fictional discourse of law then there is no real fact of the matter as to the identity of the fiction and when we are talking about one or many discourses of law. Further, there is nothing sacrosanct about non-overlapping territories in the fictional individuation of legal systems. If other legal systems with common territorial extent are recognised as such within the jurisprudence of a domestic legal system, albeit qualified as sui generis, then that domestic legal system admits of legal pluralism by its own conceptual standards.

\section{Law \& morality / fiction \& reality}

Leiter argues that there is no principled demarcation between moral and legal norms. ${ }^{42}$ The concepts of morality and legality do not map onto natural kinds that yield greater precision to scientific inquiry. He concludes that the attempt to analyse such a demarcation should be abandoned. Yet, there is a principled demarcation made available by the stance of legal fictionalism: that between norms featuring in realistic and fictional discourses, respectively. This demarcation remains viable, as the proposed legal fictionalism was not motivated by fictionalism about moral and other normative truth claims, per se. Leiter has available to him an obvious response to this fictionalist demarcation. He can deny that morality arises as part of a realistic discourse. Indeed, Leiter expresses confidence that our best explanatory theory of the world will probably not appeal to moral norms. ${ }^{43}$ However, a Procrustean standard is at work, here. Moral truths may not be the kind of truth that can contribute to an explanatory theory, nor argument to the best explanation the sole measure of the real.

Much of the same moral vocabulary and concepts are employed as part of a useful fiction of law and to express real moral commitments. The normative force of morality therefore explains the similar obligatory character of both legal and moral norms. In this respect, a fictional discourse of law subsumes Raz's statements from the point of view of law, as a form of non-committed normative statement. To explain statements from a point of view, Raz gives the example of a Catholic expert on Rabbinical law advising an ill-informed Jew. This example is, therefore, best explained

\footnotetext{
42 Brian Leiter, 'The Demarcation Problem in Jurisprudence: A New Case for Scepticism' (2011) 31(4) Oxford Journal of Legal Studies 663.

43 Ibid $672, \mathrm{n} 46$.
} 
as the Catholic assuming the role of a fictional storyteller. This makes better sense of the fact that the Catholic does not think that the Jew really is obliged to follow Rabbinical law. ${ }^{44}$ Further, Raz analyses the authority claimed by law as its claim of providing protected reasons for conforming action, ie, reasons for prescribed action and to exclude conflicting reasons. ${ }^{45}$ Granting Raz's analysis, the authority of law can be explained by the way in which the fiction of law describes a complete domain, entirely distinct from the complete domain of reality, though incorporating real aspects as is typical of fiction. From the legal point of view, therefore, there are only its own reasons, though they often coincide with the reasons of real morality.

Despite the totalising claim of law, realistic moral discourse may include a meta-discourse evaluating whether or not we should defect from the fictional discourse. Looking at the demarcation in the proposed way makes the practical importance of the demarcation clear. One can defect from the fictional discourse of the law, if the requirements of the law become unacceptable given one's core interests, including moral beliefs, by ceasing to engage with the discourse and adopting a purely external point of view. Reasons for deciding germane to a fictional discourse cease to be operative once one ceases to participate in the discourse. Yet, one cannot defect from a moral discourse with the same effect if it refers to real, normative states of affairs that will persist whether or not one engages in a discourse concerning them and, therefore, reasons germane to the moral discourse will remain as reasons regardless of whether or not they are entertained.

Leiter takes the practical importance attributable to the demarcation to be that morally valid norms alone are overriding in practical reasoning. He then challenges this priority of moral norms. Yet, this priority is but a likely consequence of founding the distinction between law and morality on that between fictional and realistic discourses, because only legal norms can be avoided by defecting from the relevant discourse. If there is no similar defection from a moral discourse then, clearly, morality is more likely to be the preferred direction in which to jump in the event of a conflict between law and morality. Even so, neither legal norms nor moral norms must take the form of all-or-nothing rules. Instead, either could take the form of defeasible rules or principles.

The possibility of justified defection saves a descriptive theory of law from the charge of cloaking immoral governance in the legitimising mantle of law. This is not to deny the difficulty of calculating the point at which defecting from a fictional discourse of law becomes a more optimal strategy than contributing to its maintenance. Yet, the possibility of such a calculation distinguishes legal fictionalism from the postmodern quietism of Patterson. ${ }^{46}$ The latter removes any strong distinction between the real and the fictional, and places all discourses on the same critical level. A lack of priority

\footnotetext{
44 Joseph Raz, The Authority of Law $2^{\text {nd }}$ edition (2009) 156-9.

$45 \quad$ Ibid 29.

46 Dennis Patterson, Law \& Truth (Oxford University Press, 1996) 149-50, 178-82.
} 
between discourses would prevent an external critique of the discourse of law due to the lack of a place to stand outside the discourse, to which legal argument must give way.

Of course, it is the burden of a conservative fictionalism to supply a reason to maintain a fictional discourse when truth is obviously not what is at stake. Why should we not defect from a fictional discourse of law as a matter of course? Any such reason stands in a contingent relation to participation in such a discourse, as it is not necessary that there is any single reason for participants who recognise the discourse as fictional to maintain it. Even so, we can still hypothesise that there is a probable convergence of reasons.

I think that there is often a broad strategy implicit in engagement with a fictional discourse of law that benefits both the more and less powerful, in distinct ways. On the side of the more powerful, they obtain the benefit of stability of power. They do not need to fear revolution in times of weakness, because they can invoke legal reasons that entrench their power. On the side of the less powerful, by holding the more powerful to the same legal reasons, potentially extreme power differences between the more and less powerful in society are moderated. To quote Marxist historian E P Thompson:

The rhetoric and the rules of a society are something a great deal more than a sham. In the same moment they may modify, in profound ways, the behaviour of the powerful, and mystify the powerless. They may disguise the true realities of power, but, at the same time, they may curb that power and check its intrusions. ${ }^{47}$

So, there can be something for everyone in maintaining a fictional discourse of law.

\section{Conclusion}

Legal fictionalism can be motivated by denying that there is a principled basis to differentiate between ontological commitment to legal and physical things, respectively, as is needed to hold that the former really exist in virtue of a community's acceptance of them, though the latter could not. The grades of legal fictionalism that may be motivated in this way include a strong form. Strong legal fictionalism has it that maintaining a fictional discourse of law with respect for its integrity yields independent reasons for legal decision-makers to reach conclusions that diverge from outcomes suggested by their moral or political convictions. It is suggested, both that there is a human capacity to maintain such a robust fictional discourse of law and that this describes what actually occurs to varying degrees in modern societies. Further,

47

E P Thompson, 'The Rule of Law' in Dorothy Thompson (ed), The Essential E P Thompson (The New Press, 2001) 436-8. 
there is at least one good reason to prefer the maintenance of such a discourse as an ideal of legal, adjudicative and legislative practice, and of jurisprudential scholarship.

If this much is granted then legal philosophy that prioritises real, non-legal reasons for legal decisions undermines jurisprudential fiction when internalised by its participants. Even the concept of law and associated concepts are to be analysed within a fictional discourse, so that the methodology of jurisprudence is entirely a matter of engaging with a fictional discourse of law. Importing realistic criteria to analyse the concept of law, such as empirical fruitfulness or importance and significance according to fundamental principles of human flourishing, introduces irrelevant considerations with the effect of changing the subject and distorting the discourse. In addition to disregarding the demarcation between jurisprudence and philosophy or science, such approaches break down a principled demarcation between moral and legal norms, which can be affirmed as the demarcation between fictional and realistic discourses.

As the subtitle of this article suggests, it is but a precursor to a thoroughgoing account of jurisprudence in fictionalist terms. More consideration of the implications of accepting strong legal fictionalism for the local practice and development of law is required. More needs to be said about assumptions underlying the abstract approach of strong legal fictionalism, such as what it means to respect the integrity of a fictional discourse and the human faculties that are engaged in this process. There is also a need to justify the endorsed reason for maintaining a fictional discourse of law, locating it within liberal political philosophy.

Even so, a distinctive approach to jurisprudence has been put forward, which seeks to synthesise the confidence attributed to legal formalism that it is always possible to achieve objectively correct legal decisions by means of independent legal reasoning, with a fictionalist ontology of law that grants the critics of the completeness and consistency of the legal domain, such as legal realists, their view that right answers are not really out there waiting to be discovered. 